\title{
Performance vigilance task and sleepiness in patients with sleep- disordered breathing
}

\author{
E. Sforza*, J. Haba-Rubio*, F. De Bilbao*, T. Rochat", V. Ibanez*
}

Performance vigilance task and sleepiness in patients with sleep-disordered breathing. E. Sforza, J. Haba-Rubio, F. De Bilbao, T. Rochat, V. Ibanez. (C) ERS Journals Ltd 2004. ABSTRACT: Altered vigilance performance has been documented in patients with sleep-related breathing disorders (SRBDs). Sleep fragmentation, sleepiness, respiratory disturbances and nocturnal hypoxaemia have been suggested as the pathogenesis of these deficits, yet it remains difficult to find a good correlation between performance deficits and the above factors. In the present study, which performance measure better characterised SRBD patients and the main factors implicated in these disturbances were examined.

The study group consisted of 152 patients and 45 controls, all examined using a performance vigilance task and subjective sleepiness assessment. Speed and accuracy in the psychomotor vigilance task (PVT) were measured in patients and controls. Objective daytime sleepiness was assessed in the patient group using the maintenance of wakefulness test.

In comparison with controls, PVT accuracy rather than speed seems to be affected in SRBD patients, with lapses and false responses significantly greater in patients with more severe objective sleepiness and higher apnoea/hypopnoea index. Although slowing and increased variability in reaction time were associated with shorter sleep latency in the maintenance of wakefulness test, subjective sleepiness, sleep fragmentation, nocturnal hypoxaemia and apnoea/hypopnoea index influenced mainly PVT accuracy.

It is concluded that vigilance impairment, sleep fragmentation and severity of disease may partially and differentially contribute to the diurnal performance consequences found in sleep-related breathing disorders. Since the psychomotor vigilance task worsening is more marked in accuracy that in speed, measurement of lapses and false responses would better characterise the degree of diurnal impairment in these patients. Eur Respir J 2004; 24: 279-285.
* Sleep Laboratory, Dept of Psychiatry, and

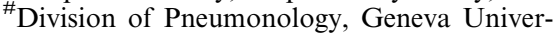
sity Hospital, Geneva, Switzerland.

Correspondence: E. Sforza

Laboratoire de Sommeil

Dept de Psychiatrie

Hôpitaux Universitaires de Genêve

2 Chemin du Petit Bel Air

CH 1225 Chêne Bourg

Genève

Switzerland

Fax: 41223055343

E-mail: Emilia.Sforza@hcuge.ch

Keywords: Hypoxaemia performance

sleep fragmentation

sleep-related breathing disorders sleepiness

Received: August 112003

Accepted after revision: February 292004
It is well known that the main consequence of sleep-related breathing disorders (SRBDs) is excessive daytime sleepiness associated with several adverse effects, including impaired daytime performance [1], neuropsychological dysfunction $[2,3]$ and increased risk of road traffic accidents [4-6]. Since the meaning of daytime dysfunction varies between patients and includes not only sleepiness but also reduced capacity to sustain attention and concentration [7], impaired short-term memory [8], and altered verbal learning and fluency [9], more objective measures of vigilance and attention have been developed in SRBD patients, such as the performance vigilance test $[10,11]$ and the Oxford Sleep Resistance (OSLER) test [12]. Using these tests, several studies have shown that patients diagnosed with obstructive sleep apnoea (OSA) syndrome frequently exhibit some degree of performance impairment $[7,13,14]$ that improves after treatment $[15,16]$. The problem in interpreting these results stems from whether the observed deficit is present in all patients with SRBD, mildto-moderately affected patients being frequently unaware of their alertness deficit and the decrement in their performance. Moreover, from a clinical perspective, unanswered questions remain as to the relationship between severity of SRBD, sleepiness and performance consequences. In other words, is a patient who reports high levels of sleepiness and having severe SRBD likely to show impaired diurnal performance? Additionally, which measure of reduced performance best describes the diurnal impairment in these patients? These two questions are of substantial relevance in the estimation of the actual daytime effects of the disorder [17] and, consequently, efficacy of therapy.

The present study analysed subjective and objective alertness, as well as performance, in a large sample of patients with SRBD exhibiting differing severity of sleep-disordered breathing. The first aim of the study was to assess whether a performance vigilance task, sensitive to reduced alertness, differentiates patients on the basis of SRBD severity, and which performance measure, i.e. accuracy or speed, better identifies patients with greater daytime impairment. Second, which diurnal or nocturnal variables most influence performance speed and accuracy was examined in these patients.

\section{Methods}

\section{Subjects}

Between March 2002 and January 2003, all consecutive patients referred to the sleep laboratory (Dept of Psychiatry, Geneva University Hospital, Geneva, Switzerland) for evaluation of snoring, witnessed apnoeas and daytime sleepiness were included. From the polysomnographic study 
register, 220 patients were identified. Exclusion criteria were: 1) previous treatment for sleep apnoea with nasal continuous positive airway pressure, corrective upper airway surgery or a mandibular advancement device $(n=4)$; 2) the presence of other sleep disorders, such as narcolepsy or periodic leg movements $(n=4) ; 3)$ refusal to perform the maintenance of wakefulness test (MWT) $(n=5) ; 4)$ previous diagnosis of a psychiatric or neurological disease, or evidence on clinical and medical examination of a neurological or psychiatric disorder $(n=30)$; and 5) intake of any drug, such as stimulants, hypnotics, benzodiazepines and antidepressants $(n=25)$. Of the original sample, 152 patients, 53 females and 99 males, aged $52.9 \pm 10.8$ yrs (mean $\pm \mathrm{SD}$ ), with a body mass index (BMI) of $31.4 \pm 6.6 \mathrm{~kg} \cdot \mathrm{m}^{-2}$, neck circumference of $41.1 \pm 6.1 \mathrm{~cm}$ and apnoea/hypopnoea index (AHI) of $37.7 \pm 29.9$, fulfilled the inclusion criteria. Patients were informed that some of the data collected would be used for research purposes and gave written informed consent. For descriptive analysis, AHI cutoff points of $\leqslant 10$ (i.e. snorers) and $>10-30,>30-50$ and $>50$ (i.e. mild, moderate and severe OSA) were used to define severity of sleep-disordered breathing.

As controls, 45 volunteers, 10 females and 35 males, aged $42.8 \pm 13.1 \mathrm{yrs}$, with a BMI of $25.2 \pm 4.2 \mathrm{~kg} \cdot \mathrm{m}^{-2}$ and neck circumference of $33.1 \pm 5.4 \mathrm{~cm}$, were considered. Subjects were in good health, as determined by medical history and examination, and all were medication-free. All subjects had regular sleep/wake schedules, as assessed by a 1-week sleep $\log$, and none showed symptoms of neurological, psychiatric or sleep disorders at the clinical interview.

\section{Nocturnal sleep studies}

The polysomnography included seven electroencephalograms, right and left electro-oculograms, and one electromyogram of chin muscles for conventional sleep staging. Respiratory airflow was monitored using a nasal cannula connected to a pressure transducer (PTAF2; Pro-Tech, Inc., Minneapolis, MN, USA), thoracic and abdominal respiratory movements with piezoelectric strain gauges, and tracheal sound using a microphone. Arterial oxygen saturation $\left(\mathrm{Sa}, \mathrm{O}_{2}\right)$ was continuously monitored using a finger oximeter.

Sleep was scored using the criteria of RECHTSCHAFFEN and KALES [18] in epochs of $20 \mathrm{~s}$ by a scorer experienced in the use of standard guidelines. As indices of sleep fragmentation, the number of arousals and awakenings were defined. Arousals were scored according to American Sleep Disorders Association criteria [19] as abrupt shifts in electroencephalographic frequency, irrespective of chin electromyographic changes during nonrapid eye movement (NREM) sleep but associated with a concurrent electromyographic increase in rapid eye movement sleep. Respiratory events were scored using standard criteria. Hypopnoeas were defined as a $\geqslant 50 \%$ reduction in airflow from the baseline value lasting $\geqslant 10 \mathrm{~s}$ and associated with $3 \%$ desaturation or an arousal. Apnoeas were defined as the absence of airflow at the nasal cannula lasting for $>10 \mathrm{~s}$. The AHI was established as the number of apnoeas plus hypopnoeas per hour of sleep. As indices of nocturnal hypoxaemia, mean $\mathrm{Sa}, \mathrm{O}_{2}$ and minimal $\mathrm{Sa}, \mathrm{O}_{2}$ recorded during sleep were used.

\section{Daytime sleepiness and performance evaluation}

All patients and controls were evaluated with an $~ 7-\mathrm{min}$ performance test and questionnaires presented every $2 \mathrm{~h}$ in five identical blocks scheduled at 09:00, 11:00, 13:00, 15:00 and 17:00 h. The sequence was as follows: Stanford Sleepiness
Scale (SSS) [20], Visual Analogue Scale (VAS) [21] and psychomotor vigilance task (PVT). In the patient group, 5 min after the end of the PVT, the MWT was administered [22]. When not involved in testing sessions, patients and controls were allowed to carry out their usual activities, such as reading, writing, listening to music and watching television, under the supervision of at least one experimenter. They were not allowed to consume alcohol or caffeine or to take medications that could induce sleepiness during the protocol. Lying down, sleeping and vigorous physical activity were not permitted. During test sessions, subjects were seated in an isolated room, free of distraction, and were instructed to complete the task. The subjects received no verbal feedback from the experimenters during the study. Throughout the study, meals were served at 08:00 and 12:00 h, with snacks and beverages available ad libitum between tests.

The level of subjective sleepiness with regard to the past month was assessed in patients and controls by administration of the Epworth Sleepiness Scale (ESS) [23] the morning before the scheduled blocks.

The PVT is a sustained visual vigilance/attention reactiontime (RT) test used to measure behavioural alertness [24, 25]. The PVT was presented on a computer screen and consisted of a series of 100 images of a white dot on a black screen visible for $50 \mathrm{~ms}$ with a random interstimulus interval of 3-7 s. The entire block lasted $\sim 7 \mathrm{~min}$. Subjects were instructed to press a button when the stimulus appeared on the screen as fast as they could while still maintaining accuracy. As regards the PVT, the following variables were considered for each session and for the overall blocks: mean RT calculated only from correct responses, as a measure of speed, i.e. the interval between stimulus onset and key pressure; the SD of the intra-individual RT (RT variability), as a measure of performance variability; the number of false responses (RT of $<50 \mathrm{~ms}$ ); and the number of lapses (RT $>1,000 \mathrm{~ms}$ ), as measures of performance accuracy and indicative of reduced behavioural alertness respectively.

The SSS is a Likert-type seven-point scale [20] on which the subject was asked to indicate the scale value that best described their level of sleepiness/alertness. Steps range from "feeling alert and vital" to "almost in reverie, lost struggle to remain awake". For the VAS [21], each subject was required to assess "how do you feel right now" with respect to the adjective "sleepy", making a stroke with a pen on a $10-\mathrm{cm}$ line, between the extremes of "not at all" and "very much". The dependent variable was the distance from the left end (not at all) of the line and the subject's mark.

In the patient group, objective daytime sleepiness was assessed using the MWT according to standard criteria [22]. This was carried out by asking the patients to sit in a quiet dark room and try to stay awake for five sessions scheduled at 09:00, 11:00, 13:00, 15:00 and 17:00 h. All tests were terminated $15 \mathrm{~min}$ after sleep onset or after 40 min without sleep, and mean sleep latency was calculated for the five naps.

For each of the neurobehavioural assays and the MWT, daily means over the five test evaluations in the period 09:00-17.00 $\mathrm{h}$ were computed to assess the profiles of sleepiness and performances across patients and controls. All controls and patients provided complete data for the PVT, the SSS and the VAS, whereas MWT data were available only for the patient group.

\section{Statistical analyses}

For variations in performances and sleepiness measures, two-way analysis of variance (ANOVA) for repeated measures was conducted with groups (control versus AHI type) as 
the between factor and session (different times of testing) as the repeated measure. Since no variations in any of the sleepiness and PVT measures were noted over time, the data of the five sessions were pooled to obtain a mean diurnal value for all sleepiness and PVT measures, and one-way ANOVA for multiple comparison with Bonferroni correction was performed in order to assess the difference between controls and patients and between patient groups.

The Pearson correlation test with Bonferroni correction was used to identify variables correlated with mean RT, mean RT variability and numbers of lapses and false responses. Multivariate regression analysis was performed in order to define the contribution of anthropometric, diurnal and nocturnal variables in explaining performance variations in the patient group.

Results are presented as mean \pm SD. A p-value of $\leqslant 0.01$ was accepted as significant.

\section{Results}

\section{Characteristics of the patients}

Table 1 shows the values of the clinical, anthropometric and polysomnographic parameters among the analysed patients stratified according to AHI. As expected, snorers were younger $(\mathrm{p}=0.03)$ and exhibited a lower BMI $(\mathrm{p}=0.001)$ and neck circumference $(\mathrm{p}=0.09)$ compared to patients with OSA. With regard to polysomnographic parameters, table 1 reveals significant differences between groups. Patients with severe OSA showed a lower nocturnal $\mathrm{Sa}, \mathrm{O}_{2}$ and amount of slow wave sleep and a higher respiratory disturbance index, a higher proportion of stages 1 and 2 NREM sleep and more arousals. During the daytime, measurement of subjective sleepiness revealed no differences between groups, although patients with higher AHIs (AHI>50) showed a lower mean sleep latency in the MWT ( $\mathrm{p}=0.01)$ (table 2).

\section{Daytime sleepiness and psychomotor vigilance task measures}

Figure 1 illustrates the time course of SSS score, VAS score and PVT performance in controls and SRBD patients. ANOVA for repeated measures showed no effect of time of day on SSS $\left(F_{4,76}=1.63\right.$ (where 4 and 76 are the number of degrees of freedom), $\mathrm{p}=0.16)$ and $\operatorname{VAS}\left(\mathrm{F}_{4,76}=2.09, \mathrm{p}=0.08\right)$ and no interaction for SSS $\left(\mathrm{F}_{16,8}=1.40, \mathrm{p}=0.14\right)$ and VAS $\left(\mathrm{F}_{16,8}=0.55, \mathrm{p}=0.92\right)$, controls and patients showing a similar trend. ANOVA for repeated measures revealed no significant effect of time of day and no interaction for any PVT measure, i.e. RT (time of day $\mathrm{F}_{4,76}=1.10, \mathrm{p}=0.35$; interaction $\mathrm{F}_{16,8}=0.97$, $\mathrm{p}=0.48$ ), RT variability (time of day $\mathrm{F}_{4,76}=0.035, \mathrm{p}=0.99$; interaction $\mathrm{F}_{16,8}=0.70, \mathrm{p}=0.79$ ), lapses (time of day $\mathrm{F}_{4,76}=1.32$, $\mathrm{p}=0.26$; interaction $\mathrm{F}_{16,8}=0.92, \mathrm{p}=0.54$ ) and false responses (time of day $\mathrm{F}_{4,76}=1.79, \mathrm{p}=0.09$; interaction $\mathrm{F}_{16,8}=1.31$, $\mathrm{p}=0.19$ ), showing considerable uniformity in controls and patients.

In the patient group, ANOVA for repeated measures revealed a significant effect of time of day on sleep latency in the MWT $\left(\mathrm{F}_{4,76}=15.3, \mathrm{p}<0.0001\right)$. Significant differences occurred between the lower values obtained at 13:00 $\mathrm{h}$ and the highest value obtained at 17:00 h. Despite a significant major effect of MWT session, no significant interaction was present when patients were examined on the basis of their AHI $\left(F_{12,6}=1.7, p=0.06\right)$, even though shorter sleep latencies were obtained in patients having an AHI of $>50$.

Since no strong variations according to time of day in sleepiness and PVT measures occurred in the control or patient groups, the data from the five sessions were pooled in order to obtain mean diurnal values for all sleepiness and PVT measures. Table 2 shows the mean values for subjective daytime sleepiness and PVT in controls and SRBD patients. Controls were younger, with a significantly lower BMI and neck circumference $(\mathrm{p}<0.001)$. Statistical analysis revealed that SRBD patients showed significantly reduced alertness and worsened performances compared to controls. They

Table 1.-Anthropometric, clinical and polysomnographic data from snorers and obstructive sleep apnoea (OSA) patients stratified according to apnoea/hypopnoea index (AHI)

\begin{tabular}{|c|c|c|c|c|c|}
\hline & \multirow[t]{2}{*}{ Snorers $^{\#}$} & \multicolumn{3}{|c|}{ OSA patients } & \multirow[t]{2}{*}{ p-value } \\
\hline & & AHI $>10-30$ & AHI $>30-50$ & $\mathrm{AHI}>50$ & \\
\hline Subjects n & 32 & 44 & 29 & 47 & \\
\hline Age yrs & $48.7 \pm 9.3$ & $52.4 \pm 10.0$ & $54.0 \pm 11.4$ & $55.6 \pm 11.6$ & NS \\
\hline $\mathrm{BMI} \mathrm{kg} \cdot \mathrm{m}^{-2}$ & $28.8 \pm 6.1$ & $30.4 \pm 6.8$ & $30.3 \pm 5.4$ & $34.5 \pm 6.5$ & 0.001 \\
\hline Neck circumference $\mathrm{cm}$ & $39.7 \pm 3.8$ & $40.7 \pm 3.3$ & $40.2 \pm 8.1$ & $43.1 \pm 7.4$ & NS \\
\hline AHI events $\cdot h^{-1}$ & $5.9 \pm 2.4$ & $19.5 \pm 5.7$ & $39.8 \pm 5.9$ & $75.4 \pm 20.2$ & 0.001 \\
\hline Minimal $S \mathrm{a}, \mathrm{O}_{2} \%$ & $85.5 \pm 4.5$ & $81.2 \pm 4.8$ & $76.9 \pm 7.8$ & $68.8 \pm 5.7$ & 0.001 \\
\hline $\mathrm{Sa}, \mathrm{O}_{2} \%$ & $93.4 \pm 1.8$ & $92.6 \pm 1.2$ & $92.2 \pm 1.6$ & $89.8 \pm 3.8$ & 0.001 \\
\hline \multicolumn{6}{|l|}{ NREM sleep min } \\
\hline Stage 1 & $54.0 \pm 21.0$ & $67.2 \pm 23.1$ & $73.3 \pm 24.1$ & $101.1 \pm 39.2$ & 0.001 \\
\hline Stage 2 & $208.7 \pm 48.9$ & $201.5 \pm 52.3$ & $206.4 \pm 58.3$ & $235.6 \pm 56.9$ & 0.01 \\
\hline Stage 3-4 & $80.7 \pm 25.4$ & $58.5 \pm 24.4$ & $47.8 \pm 28.6$ & $21.4 \pm 27.1$ & 0.001 \\
\hline REM sleep min & $89.8 \pm 23.6$ & $68.9 \pm 26.5$ & $61.5 \pm 29.9$ & $54.7 \pm 32.3$ & 0.001 \\
\hline TST min & $433.2 \pm 55.0$ & $396.4 \pm 63.9$ & $388.9 \pm 81.2$ & $412.8 \pm 76.9$ & NS \\
\hline WASO min & $76.0 \pm 45.8$ & $106.5 \pm 58.6$ & $120.7 \pm 66.7$ & $112.4 \pm 60.5$ & NS \\
\hline SE \% & $82.4 \pm 9.1$ & $76.6 \pm 11.2$ & $74.2 \pm 14.1$ & $77.2 \pm 12.0$ & NS \\
\hline Awakening $\mathrm{n}$ & $17.9 \pm 14.6$ & $20.5 \pm 10.4$ & $20.4 \pm 16.0$ & $18.1 \pm 11.6$ & NS \\
\hline Arousal n & $120.7 \pm 36.6$ & $288.8 \pm 35.1$ & $344.6 \pm 53.7$ & $522.0 \pm 63.4$ & 0.001 \\
\hline MWT min & $25.4 \pm 12.3$ & $23.0 \pm 11.5$ & $24.2 \pm 14.0$ & $17.4 \pm 14.3$ & 0.01 \\
\hline
\end{tabular}

Data are presented as mean \pm SD. AHI: apnoea/hypopnoea index; BMI: body mass index; $\mathrm{Sa}_{2} \mathrm{O}_{2}$ : arterial oxygen saturation; NREM: nonrapid eye movement; REM: rapid eye movement; TST: total sleep time; WASO: wake time after sleep onset; SE: sleep efficiency; MWT: sleep latency in maintenance of wakefulness test; NS: nonsignificant. ${ }^{\#}$ : AHI of $\leqslant 10$; ${ }^{\text {: }}$ one-way analysis of variance. 
Table 2. - Anthropometric data, subjective sleepiness scores and performance measure results in controls and patients stratified according to apnoea/hypopnoea index (AHI)

\begin{tabular}{|c|c|c|c|c|c|}
\hline & \multirow[t]{2}{*}{ Controls } & \multirow[t]{2}{*}{ Snorers ${ }^{\S}$} & \multicolumn{3}{|c|}{ OSA patients } \\
\hline & & & $\mathrm{AHI}>10-30$ & $\mathrm{AHI}>30-50$ & $\mathrm{AHI}>50$ \\
\hline Age yrs & $42.9 \pm 13.1^{* * *}$ & $48.7 \pm 9.3$ & $52.4 \pm 10.0$ & $54.0 \pm 11.3$ & $55.6 \pm 11.6$ \\
\hline ESS & $6.9 \pm 2.7^{\oplus}$ & $9.7 \pm 5.7$ & $10.3 \pm 4.2$ & $10.6 \pm 5.9$ & $10.4 \pm 5.4$ \\
\hline SSS & $2.3 \pm 0.9$ & $2.7 \pm 1.1$ & $2.3 \pm 0.9$ & $2.9 \pm 1.2$ & $2.5 \pm 1.3$ \\
\hline VAS & $2.2 \pm 1.6$ & $2.7 \pm 2.1$ & $2.0 \pm 1.7$ & $2.8 \pm 2.1$ & $2.4 \pm 1.9$ \\
\hline $\mathrm{RT} \mathrm{ms}$ & $339.5 \pm 55.1 * *$ & $364.8 \pm 65.1$ & $391.0 \pm 84.9$ & $368.5 \pm 64.7$ & $384.2 \pm 83.1$ \\
\hline RT variability $\%$ & $72.3 \pm 25.1$ & $80.8 \pm 26.5$ & $84.5 \pm 28.0$ & $80.5 \pm 24.3$ & $86.2 \pm 36.6$ \\
\hline False response $\mathrm{n}$ & $0.9 \pm 2.4$ & $1.2 \pm 0.3$ & $1.8 \pm 1.9$ & $1.8 \pm 1.7$ & $4.9 \pm 8.7^{\# \#}$ \\
\hline Lapse $\mathrm{n}$ & $1.6 \pm 0.9$ & $1.5 \pm 0.6$ & $1.7 \pm 1.5$ & $1.4 \pm 0.6$ & $3.1 \pm 2.6^{+}$ \\
\hline
\end{tabular}

Data are presented as mean \pm SD. ESS: Epworth Sleepiness Scale; SSS: Stanford Sleepiness Scale; VAS: Visual Analogue Scale; RT: reaction time. \$: AHI of $\leqslant 10 ; * *: \mathrm{p}<0.01$; $^{\uparrow} \mathrm{p}<0.005{ }^{* * *}: \mathrm{p}<0.001$ versus patients (analysis of variance (ANOVA)); ${ }^{\# \#: ~} \mathrm{p}<0.01 ;{ }^{+}: \mathrm{p}<0.005$, between patients (ANOVA).

reported high ESS scores ( $\mathrm{p}=0.003$ ) and showed worse mean RTs $(p=0.01)$ compared to controls, without differences in subjective estimates of sleepiness, i.e. SSS and VAS, and RT variability. A trend to progressive worsening of RT and RT variability was noted among patients with differences, not, however, reaching significance. Overall, control subjects made fewer errors than patients with SRBD, with a significant and strong rise in "lapses" $(\mathrm{p}=0.004)$ in patients with severe OSA.

\section{Correlation analysis}

The results of Pearson correlation analysis of PVT measurements versus clinical and polysomnographic parameters and indices of sleepiness in the patient group are shown in table 3. BMI slightly correlated with all performance scores. Subjective perception of daytime sleepiness (ESS, SSS and VAS) and sleep latency in the MWT contributed significantly to RT speed and variability, as well as to lapses. Conversely, objective measures of SRBD severity, i.e. AHI, nocturnal hypoxaemia, number of arousals and total sleep time, correlated strongly with false responses and lapses. A stepwise multiple regression analysis including AHI, nocturnal hypoxaemia and indices of daytime sleepiness as independent variables, and PVT measurements as dependent variables, showed that sleepiness and severity of SRBD were related to performance scores, with differing relative contributions. For RT, a model including the MWT and SSS explains the $12 \%$ of variance, with a greater contribution of sleep latency in the MWT $(10 \%)$. Sleep latency in the MWT $(12 \%)$ and $\mathrm{Sa}, \mathrm{O}_{2}(2 \%)$ explained the $14 \%$ of variance in $\mathrm{RT}$ variability. For false responses, a model including the ESS and the $\mathrm{Sa}, \mathrm{O}_{2}$ explained, respectively, 14 and $9 \%$ of the variance in the number of false responses. The number of arousals $(23 \%)$, subjective daytime sleepiness as defined by the ESS score ( $9 \%), \mathrm{Sa}, \mathrm{O}_{2}(7 \%)$ and AHI (2\%), mostly contributed to the variance of false responses, with a greater contribution of indices of sleep fragmentation and subjective sleepiness.

\section{Discussion}

The present study examined the relation between performance deficit, daytime sleepiness and indicators of SRBD in a large sample of patients with varying degrees of sleepdisordered breathing. The relatively large sample of patients and the use of different measures of subjective and objective alertness were expected to characterise better the altered diurnal impairment of these patients and the main factors contributing to their performance impairment. In comparison with controls, the present patients reported greater sleepiness and worse performance as regards speed and variability, which were, however, unrelated to measures of sleep-related breathing disturbances, no significant differences being apparent between patient groups. In contrast, accuracy of performance, i.e. lapses and false responses, were better predictors of daytime impairment, less accuracy being found in patients with higher AHI and more severe daytime sleepiness. Finally, although objective assessment of SRDB (hypoxaemia, AHI and sleep fragmentation) appeared to influence performance accuracy, subjective and objective sleepiness contributed more significantly to impaired RT.

The first finding of the present study is that, compared to controls, performance impairment was evident in SRBD patients, affecting both speed and accuracy. However, although lowered PVT speed and variability did not differentiate patients on the basis of sleepiness and respiratory disturbance index, the accuracy indices were more affected by severity of disease and diurnal sleepiness, lapses and false responses being significantly greater in patients with more severe sleepiness in the MWT, and higher AHI. Therefore, despite the fact that the PVT is a quick and easy tool for evaluating the detrimental effect of SRBD on vigilance/attention performance, analysing RT alone does not give a comprehensive view of fluctuation in vigilance. Analysis of omissions and false responses provides a more sensitive index in the assessment of diurnal impairment. The current finding is also consistent with results from studies using the OSLER test $[13,14]$, in which the number and distribution of omissions is a useful means of identification of patients with sleepiness, and, consequently, at potentially increased risk of occupational and driving accidents.

The second interesting finding of the present study is that, despite sleepiness, sleep fragmentation and severity of disease being potential causes of performance impairment in SRBD patients, any of these factors may account for the individual differences in performance decrement, some patients being more vulnerable to daytime consequences. Earlier reports [24-26] assumed that subjective and objective sleepiness vary in parallel with changes in performance following circadian [26] and homeostatic processes [25], supporting the hypothesis that sleepiness is the key factor underlying performance impairment. However, it is still unclear whether performance is directly affected by sleepiness or whether performance and sleepiness simply co-vary [27]. As in healthy sleep-deprived subjects [27], no relationship was found between sleepiness and performance speed deficits, RT and RT variability being consistently similar in the patient groups. There was also a temporal dissociation between the profiles of subjective sleepiness and PVT accuracy, with lapses and false responses 
a)

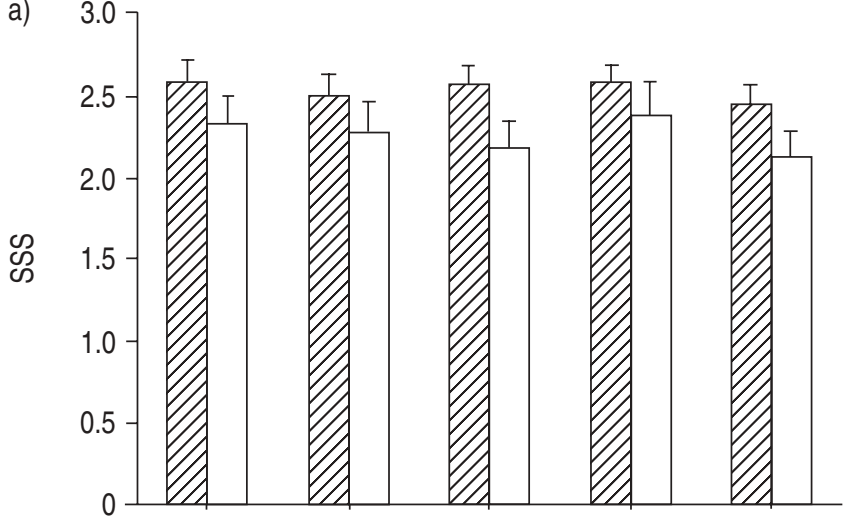

c)

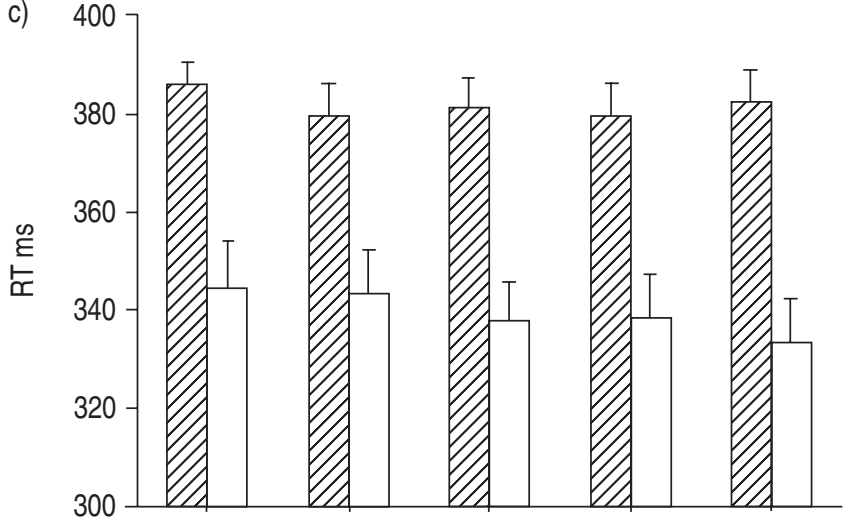

e)

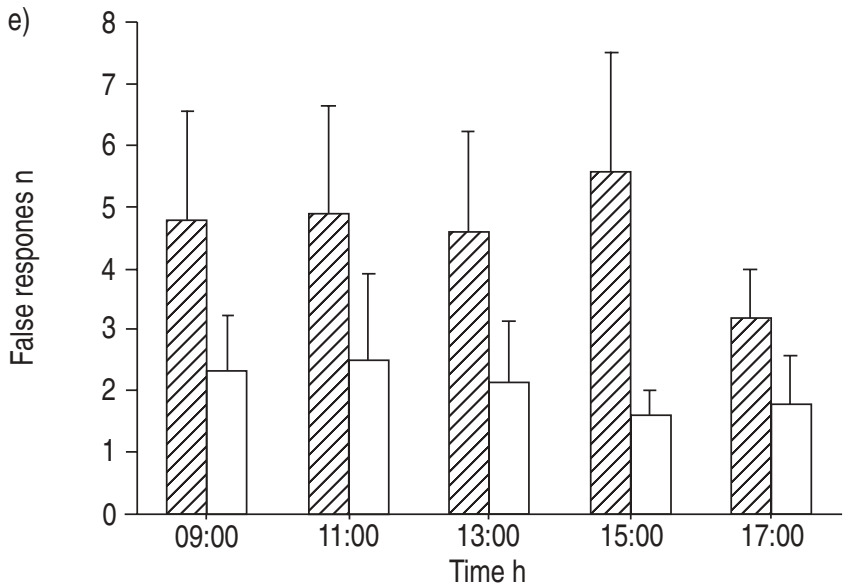

b)

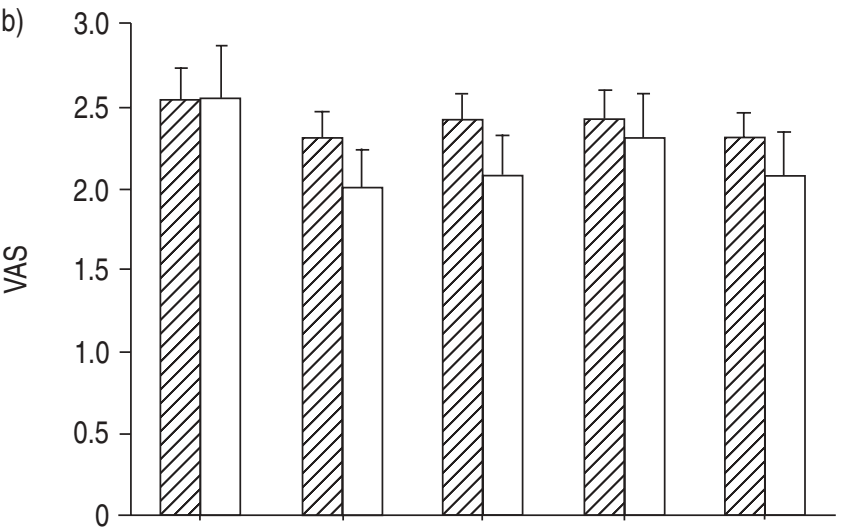

d)
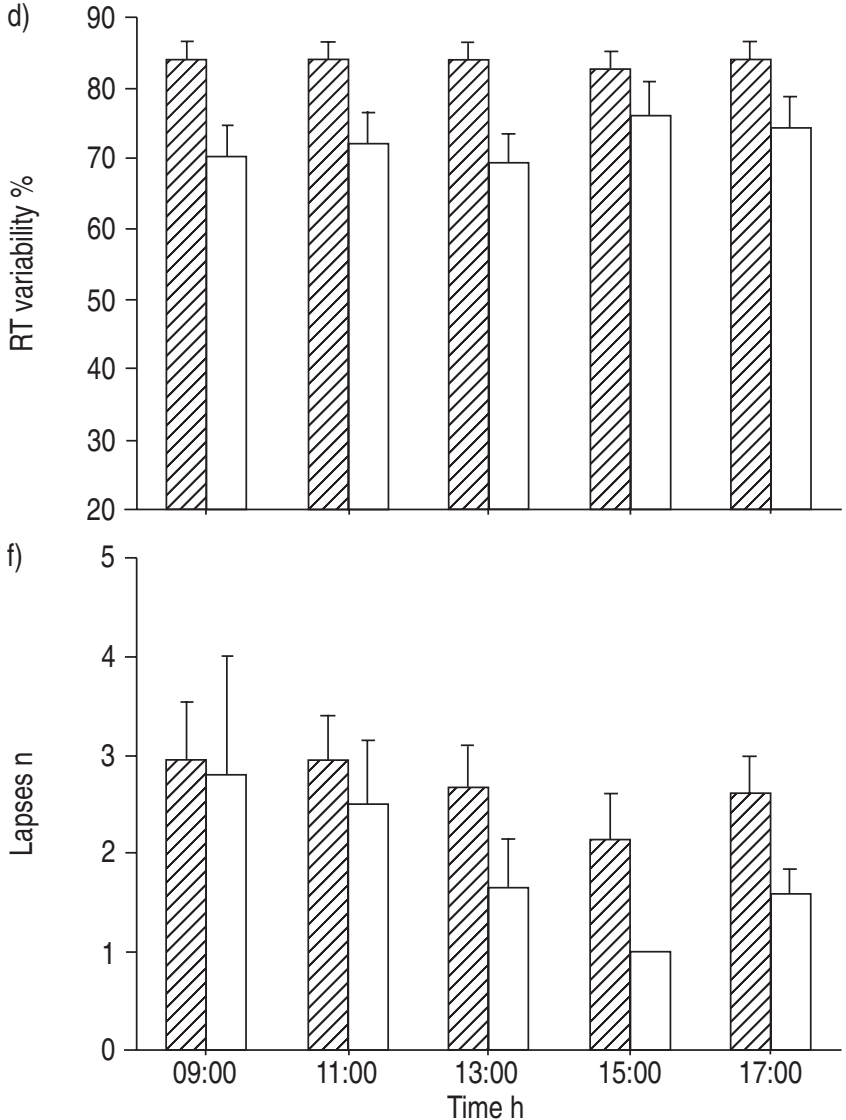

Fig. 1.-Subjective sleepiness measured using the a) Stanford Sleepiness Scale (SSS) and b) Visual Analogue Scale (VAS), and c) reaction time (RT), d) RT variability, e) false responses and f) lapses in controls ( $\square$ ) and sleep-related breathing disorder patients (ש) in the five sessions at the indicated times. Data are presented as mean \pm SD. Despite similarity in SSS and VAS, patients showed worsened RT and increased false responses and lapses compared to controls, without influence of time of day.

higher when the patient was objectively, but not subjectively, sleepy. Despite the fact that the repetitive and unchallenging nature of the tasks minimises factors modulating motivation [28], and that the duration and complexity of the present PVT measurement [29] facilitate dissociation between performance and sleepiness, it can be suggested that sleepiness and impaired performance are not physiologically equivalent phenomena in SRBD patients. First, it could be hypothesised that, at the beginning of the disease, a progressive dysfunction in systems underlying attention and alertness would be present, allowing patients to achieve a state of equilibrium in which alertness and performance are maintained at a stable, albeit reduced, level. As a consequence of this adaptive process, the patient would not be able to perceive changes in alertness and performance and would score alert by subjective estimation, explaining the worsening PVT speed and absence of relationship with sleepiness. Secondly, it should be borne in mind that, in patients with SRBD, inability to stay awake rather than increased sleep propensity [30] occurs, patients able to mask the effects of their sleepiness making increased efforts during the time of testing to fight sleepiness. The lack of a significant effect of sleepiness on RT speed and its influence on lapses and omissions seems to suggest that the main difference between SRBD patients and controls may not be the consequences of their altered perception and motivation but rather their inability to maintain constant attention and alertness [31].

In experimental studies, sleep loss [32, 33] and sleep fragmentation [34, 35] have been recognised as the two variables mediating sleepiness and producing reduced 
Table 3. - Pearson correlation coefficient between psychomotor vigilance task measures and diurnal and nocturnal parameters

\begin{tabular}{|c|c|c|c|c|}
\hline & RT & RT variability & False responses & Lapses \\
\hline Age & -0.076 & -0.079 & -0.101 & -0.135 \\
\hline BMI & -0.175 & 0.174 & 0.232 & $0.297 * *$ \\
\hline Neck circumference & 0.143 & 0.196 & 0.285 & $0.391 * * *$ \\
\hline Total sleep time & $0.219 * *$ & 0.190 & 0.272 & $0.346^{* * *}$ \\
\hline Sleep efficiency & 0.125 & 0.068 & 0.185 & 0.194 \\
\hline Arousal & 0.081 & 0.155 & $0.322^{\bullet}$ & $0.483^{* * *}$ \\
\hline Awakening & 0.035 & 0.061 & -0.116 & 0.014 \\
\hline AHI & 0.065 & 0.100 & $0.340^{\bullet}$ & $0.416^{* * *}$ \\
\hline Minimal $\mathrm{Sa}_{\mathrm{a}} \mathrm{O}_{2}$ & -0.047 & -0.083 & $-0.279^{* *}$ & $-0.454 * * *$ \\
\hline Mean $\mathrm{Sa}_{\mathrm{a}} \mathrm{O}_{2}$ & -0.123 & $-0.024^{\top}$ & $-0.329^{\bullet}$ & $-0.421 * * *$ \\
\hline SSS & $0.281 * * *$ & $0.334 * * *$ & 0.192 & $0.345^{\bullet}$ \\
\hline VAS & $0.240^{\bullet}$ & $0.290 * * *$ & 0.152 & $0.332^{\bullet}$ \\
\hline ESS & $0.192 * *$ & $0.229^{\top}$ & $0.377^{* * *}$ & $0.392^{* * *}$ \\
\hline MWT & $-0.314 * * *$ & $-0.342 * * *$ & -0.229 & $-0.403 * * *$ \\
\hline
\end{tabular}

RT: reaction time; BMI: body mass index; AHI: apnoea/hypopnoea index; $\mathrm{Sa}_{2} \mathrm{O}_{2}$ : arterial oxygen saturation; SSS: Stanford Sleepiness Scale; VAS: Visual Analogue Scale; ESS: Epworth Sleepiness Scale; MWT: sleep latency in maintenance of wakefulness test. ${ }^{* *}: \mathrm{p}<0.01 ;{ }^{\natural}: \mathrm{p}<0.005 ;{ }^{* * *}: \mathrm{p}<0.001$.

performance in cognitive and vigilance-based tests [36, 37]. In SRBD patients, sleep fragmentation [38, 39], level of hypoxia per se $[3,40,41]$ and the intermittent nature of the hypoxic stimulus [42] may generate permanent dysfunction of the frontal brain areas operating in executive function. A focus of the present study was to define which factor, i.e. sleepiness, sleep fragmentation or measures of SRBD severity, most affects performance decrement. Although RT variability and speed were related to all scores of daytime sleepiness, sleep fragmentation and severity of respiratory disturbances, e.g. hypoxaemia and AHI, seem to cause a significant deterioration in accuracy, false responses and lapses, markedly greater in severe patients However, although sleepiness, SRBD severity and sleep fragmentation appeared to account for PVT speed and accuracy in the present patients, these factors accounted for only a small proportion of PVT measures. In the total study sample, hypoxaemia explained only $7-9 \%$ of the variance in RT accuracy, whereas the number of arousals affected only $23 \%$ of the variance in lapses. These findings indicate that performance deficit is probably a multifactorial phenomenon involving multiple and inter-related components, affecting speed and accuracy differently.

Interpretation of the present results is necessarily affected by certain limitations. First, there was no true control group, composed of subjects matched for age, and age differences were present between AHI patient groups, suggesting that some of the present findings could be explained by an effect of age on performance. However, if speed of RT is usually the first variable influenced by age [43], no effect of age on accuracy occurs due to the fact that the PVT involves only early cognitive processes, with no demand on memory and attention [44]. A further consideration is that an optimal measure of cognitive dysfunction may not have been obtained in the present patients, PVT not allowing assessment of whether perception, immediate processing or short-term memory are most affected in SRBD patients. As a result, replication of this study with a wide range of performance measures under electroencephalographic recording, including event-related potentials [45], may provide a more sensitive measure of performance efficiency and may be useful in explaining the type of performance differences noted herein.

In conclusion, analysing performance measures in a vigilance/attention task, it was found that, compared to controls, patients with sleep-related breathing disorders function at lower daytime levels, with a decrease in accuracy rather than in speed. This finding may be of significant clinical relevance, analysis of performance accuracy ratifying more than sleepiness the adverse and potentially dangerous effects of sleep-related breathing disorders. Furthermore, although daytime sleepiness, sleep fragmentation and severity of disease appear to be associated with reduced performance, no strong relationship was detected between the overall decrease in performance and these factors, suggesting that the performance impairment in sleep-related breathing disorder patients is a multifactorial phenomenon involving multiple and inter-related components. Further studies are needed to clarify the factors underlying differences in performance impairment in patients with sleep-related breathing disorders.

Acknowledgements. The authors are grateful to B. Adjivon, B. Bertram, D. Grasset and A. Lalji for technical assistance.

\section{References}

1. Dinges DF, Kribbs NB. Performing while sleepy: effects of experimentally-induced sleepiness. In: Monk TH, ed. Sleep, Sleepiness and Performance. Chichester, John Wiley \& Sons, 1991; pp. 97-128.

2. Kim HC, Young T, Matthews CG, Weber SM, Woodward AR, Palta M. Sleep-disordered breathing and neuropsychological deficits. A population-based study. Am J Respir Crit Care Med 1997; 156: 1813-1819.

3. Bedard M, Montplaisir J, Richer F, Rouleau I, Malo J. Obstructive sleep apnea syndrome: pathogenesis of neuropsychological deficits. J Clin Exp Neuropsychol 1991; 13: 950-964.

4. Findley LJ, Fabrizio MJ, Smiley A. Simulated driving performance in patients with obstructive sleep apnea. Am Rev Respir Dis 1989; 140: 529-530.

5. Findley L, Unverzagt M, Guchu R, Fabrizio M, Buckner J, Suratt $\mathrm{P}$. Vigilance and automobile accidents in patients with sleep apnea or narcolepsy. Chest 1995; 108: 619-624.

6. Juniper M, Hack MA, George CF, Davies RJ, Stradling JR. Steering simulation performance in patients with obstructive sleep apnoea and matched controls subjects. Eur Respir $J$ 2000; 15: 590-595.

7. Cassel W, Vogel M, Moog R, Ploch T, Peter JH, Von Wichert P. 24 hours spontaneous sleep, multiple sleep latencies, reaction time and subjective sleepiness in patients with obstructive sleep apnea. Sleep Res 1991; 20A: 527.

8. Naegele B, Thouvard V, Pepin L, et al. Deficits of cognitive executive functions in patients with sleep apnea syndrome. Sleep 1995; 18: 43-52.

9. Boland LL, Shahar E, Iber C, Knopman DS, Kuo TF, Nieto 
FJ. Measures of cognitive function in persons with varying degrees of sleep-disordered breathing: the Sleep Heart Health Study. J Sleep Res 2002; 11: 265-272.

10. Dinges DF, Pack F, Williams K, et al. Cumulative sleepiness, mood disturbances and psychomotor vigilance performance decrements during a week of sleep restricted to $4-5 \mathrm{~h}$ per night. Sleep 1997; 20: 267-271.

11. Conradt R, Brandenburg U, Penzel T, Hasan J, Varri A, Peter JH. Vigilance transitions in reaction time tests: a method to describing the state of alertness more objectively. Clin Neurophysiol 1999; 9: 1499-1509.

12. Bennett LS, Stradling JR, Davies RJ. A behavioral test to assess daytime sleepiness in obstructive sleep apnoea. $J$ Sleep Res 1997; 6: 142-145.

13. Priest B, Brichard C, Aubert G, Liistro G, Rodenstein DO. Microsleep during a simplified maintenance of wakefulness test. A validation study of the OSLER test. Am J Respir Crit Care Med 2001; 163: 1619-1625.

14. Mazza S, Pepin JL, Deschaux C, Naegele B, Levy P. Analysis of error profile occurring during the OSLER test. Am J Respir Crit Care Med 2002; 166: 474-478.

15. Lojander J, Kajaste S, Maasilta P, Partinen M. Cognitive function and treatment of obstructive sleep apnea syndrome. J Sleep Res 1999; 8: 71-76.

16. Conradt R, Hochban W, Heitmann J, et al. Sleep fragmentation and daytime vigilance in patients with OSA treated by surgical maxillomandibular advancement compared to CPAP therapy. J Sleep Res 1998; 7: 217-223.

17. Engleman HM, Hirst WSJ, Douglas NJ. Under reporting of sleepiness and driving impairment in patients with sleep apnoea/hypopnoea syndrome. J Sleep Res 1997; 6: 272-275.

18. Rechtschaffen A, Kales A. A Manual of Standardized Terminology, Technique and Scoring System for Sleep Stages of Human Sleep. Los Angeles, Los Angeles Brain Information Service, Brain Information Institute, University of California at Los Angeles, 1968.

19. American Sleep Disorders Association. The Atlas Task Force. EEG arousals: scoring rules and examples. Sleep 1992; 15: 174-184.

20. Hoddes E, Dement WC, Zarcone V. The development and use of the Stanford Sleepiness Scale. Psychophysiology 1972; 9: 150 .

21. Johnson LC. Daytime sleepiness in good sleepers: measurement and correlates. In: Broughton RJ, Ogilvie RD, eds. Sleep, Arousal and Performance. Boston, Birkhauser, 1992; pp. 220-229.

22. Doghramji K, Mitler MM, Sangal RB, et al. A normative study of the maintenance of wakefulness test (MWT). Electroencephalogr Clin Neurophysiol 1997; 103: 554-562.

23. Johns MW. A new method for measuring daytime sleepiness: the Epworth Sleepiness Scale. Sleep 1991; 14: 540-545.

24. Lafrance C, Paquet J, Dumont M. Diurnal time courses in psychomotor performance and waking EEG frequencies. Brain Cogn 2002; 48: 625-631.

25. Gillberg M, Kecklund G, Akerstedt T. Relations between performances and subjective ratings of sleepiness during a night awake. Sleep 1994; 17: 236-241.

26. Monk TH. Subjective rating of sleepiness: the underlying circadian mechanism. Sleep 1987; 10: 343-353.

27. Leproult R, Coleccia EF, Berardi AM, Stickgold R, Kosslyn SM, Van Cauter E. Individual differences in subjective and objective alertness during sleep deprivation are stable and unrelated. Am J Physiol 2002; 284: R280-R290.

28. Oken BS, Kishiyama SS, Salinsky MC. Pharmacologically induced changes in arousal: effects on behavioral and electrophysiological measures of alertness and attention. Electroencephalogr Clin Neurophysiol 1995; 95: 359-371.

29. Mackworth JF. Performance decrement in vigilance, threshold, and high-speed perceptual motor task. Can J Psychol 1994; 18: 209-223.

30. Johns M. Rethinking the assessment of sleepiness. Sleep Med Rev 1998; 2: 3-15.

31. Doran SM, Van Dongen HP, Dinges DF. Sustained attention performance during sleep deprivation: evidence of state instability. Arch Ital Biol 2001; 139: 263-267.

32. Belenki G, Wesensten NJ, Yhorne DR, et al. Patterns of performance degradation and restoration during sleep restriction and subsequent recovery: a sleep dose-response study. J Sleep Res 2003; 12: 1-12.

33. Van Dongen HPA, Maislin G, Mullington JM, Dinges DF. The cumulative cost of additional wakefulness: doseresponse effects on neurobehavioral functions and sleep physiology from chronic sleep restriction and total sleep deprivation. Sleep 2003; 26: 117-126.

34. Bonnet MH. Effect of sleep disruption on sleep, performance, and mood. Sleep 1985; 8: 11-19.

35. Kingshott RN, Cosway RJ, Deary IJ, Douglas NJ. The effect of sleep fragmentation on cognitive processing using computerized topographic brain mapping. J Sleep Res 2000; 9: 353-357.

36. Bonnet MH. Cognitive effects of sleep and sleep fragmentation. Sleep 1993; 16: Suppl. 8, S65-S67.

37. Chugh DK, Weaver TE, Dinges DF. Neurobehavioral consequences of arousals. Sleep 1996; 19: Suppl. 10, S198-S201.

38. Martin SE, Engleman HM, Deary IJ, Douglas NJ. The effect of sleep fragmentation on daytime function. Am J Respir Crit Care Med 1996; 153: 328-332.

39. Jones K, Harrison Y. Frontal lobe function, sleep loss and fragmented sleep. Sleep Med Rev 2001; 5: 463-475.

40. Beebe DW, Gozal D. Obstructive sleep apnea and the prefrontal cortex: towards a comprehensive model linking nocturnal upper airway obstruction to daytime cognitive and behavioral deficits. J Sleep Res 2002; 11: 1-16.

41. Rouleau I, Decary A, Chicoine AJ, Montplaisir J. Procedural skill learning in obstructive sleep apnea syndrome. Sleep 2002; 25: 401-411.

42. Row BW, Liu R, Xu W, Kheirandish L, Gozal D. Intermittent hypoxia is associated with oxidative stress and spatial learning deficits in the rat. Am J Respir Crit Care Med 2003; 167: 1548-1553.

43. Ratcliff R, Thapar A, McKoon G. The effects of aging on reaction time in a signal detection task. Psychol Aging 2001; 16: $323-341$

44. Bonnefond A, Gisselbrecht D, Hoeft A, Eschenlauer R, Muzet A, Tassi P. Cognitive performance in middle-aged adults as a function of time of day and task load. Neurobiol Sleep-Wakefulness Cycle 2003; 3: 1-8.

45. Cote KA, Milner CE, Osip SL, Ray LB, Baxter KD. Waking quantitative electroencephalogram and auditory eventrelated potentials following experimentally induced sleep fragmentation. Sleep 2003; 26: 687-694. 